\title{
Mobile Measurements of BLACK CARBOn FOR SOURCE APPORTIONMENT STUDIES
}

\author{
Adnan Masic*, Dzevad Bibic, Imer Kamenica, Jasmin Bektesevic, \\ Vahidin Hadziabdic \& Midhat Mehuljic
}
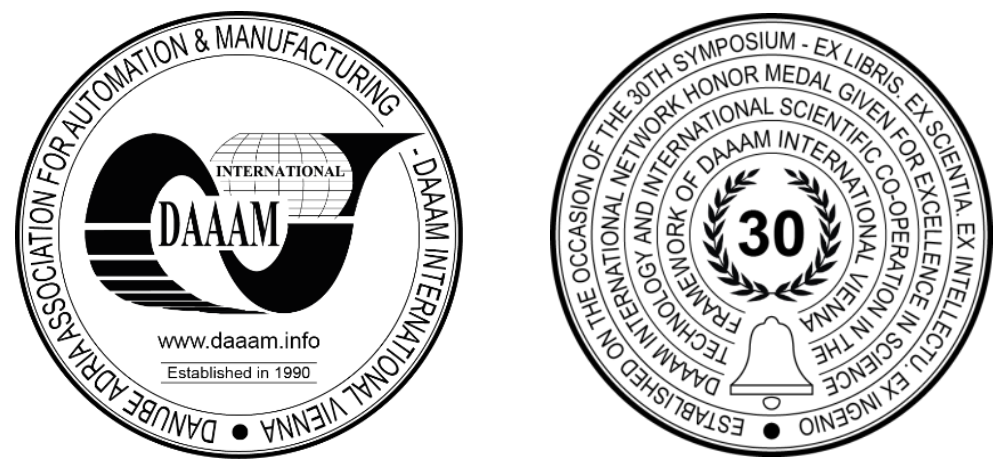

This Publication has to be referred as: Masic, A[dnan]; Bibic, D[zevad]; Kamenica, I[mer]; Bektesevic, J[asmin]; Haziabdic, V[ahidin] \& Mehuljic, M[idhat] (2020). Mobile Measurements of Black Carbon for Source Apportionment Studies, Proceedings of the 31st DAAAM International Symposium, pp.0227-0231, B. Katalinic (Ed.), Published by DAAAM International, ISBN 978-3-902734-29-7, ISSN 1726-9679, Vienna, Austria

DOI: $10.2507 / 31$ st.daaam.proceedings.031

\begin{abstract}
A new method for mobile measurements of black carbon (BC) concentration measurements is presented in this paper. An advanced pocket-sized aethalometer with 5 wavelengths and dual-spot technology was used. Different measurement locations were selected to evaluate the contribution of car emissions and biomass burning emissions during the winter campaign in heavily polluted urban environments. A model based on the Angstrom exponent is proposed for source apportionment studies. Obtained results confirmed the system's capability to distinguish BC sources with high temporal and spatial resolution.
\end{abstract}

Keywords: Black carbon; Aethalometer; Angstrom exponent; Source apportionment.

\section{Introduction}

Black Carbon (BC) is the dark, light-absorbing component of fine particulate matter. Primary sources of $\mathrm{BC}$ are the incomplete combustion of fossil fuels (FF) and biomass burning (BB). Due to its physical and chemical properties, BC plays important role the process of global climate change. Various studies shed light on the influence of BC on climate [1] and health [2]. Real-time measurement of BC concentration is possible using the device called aethalometer. The principle of work of aethalometer is depicted in Fig. 1 [3]. A regulated air pump provides the constant air flow through the instrument, which forces BC particles to go through the filter tape. Once the collection period completes, light source emits the monochromatic light, both through the sample and blank portion of the tape. Based on the intensities of these two light rays after passing through the tape and the sample, the light attenuation by BC is calculated using the following formula:

$$
A T N=-100 \ln \frac{I}{I_{0}}
$$

where $A T N$ is the optical attenuation, $I$ is the light intensity after passing through the $\mathrm{BC}$ sample, and $I_{0}$ is the light intensity after passing through the unsampled portion of the filter tape. Attenuation coefficient is calculated based on the rate of change of optical attenuation: 


$$
b_{a t n}=\frac{S(\Delta A T N / 100)}{F \Delta t}
$$

where $S$ is the spot area, $t$ is the sampling period and $F$ is the flow rate. If we divide attenuation coefficient with multiple scattering parameter, $C$, we will get the absorption coefficient:

$$
b_{a b s}=\frac{b_{a t n}}{C}
$$

Finally, BC concentration is

$$
B C=\frac{b_{a b s}}{\sigma}
$$

where $\sigma$ is the mass absorption cross section.

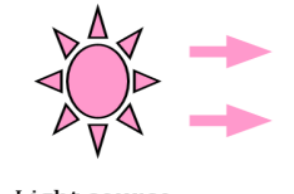

Light source

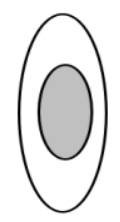

Filter

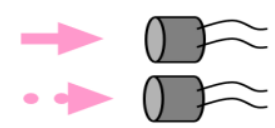

Optical detectors
Reference $\boldsymbol{I}_{\boldsymbol{o}}$

\section{Sensing $\boldsymbol{I}$}

Fig. 1. Principle of work of an aethalometer [3]

For measurements of BC, infra-red wavelength of $880 \mathrm{~nm}$ is used. However, some aethalometers are equipped with multiple light sources with different wavelengths of the light, $\lambda$. It is known that BC coming from the fossil fuel (FF) has slightly different optical properties than BC coming from the biomass burning (BB) [4]. The dependence of the absorption coefficient on wavelength of light can be written in the form

$$
b_{a b s}=k \cdot \lambda^{-\alpha}
$$

where $k$ is the constant which depends on the construction of aethalometer and $\alpha$ is the Angstrom exponent. It is dimensionless characteristic of optical properties of BC. In order to calculate the Angstrom exponent, we must have measurements for at least two different wavelengths, let's say $\lambda_{1}$ and $\lambda_{2}$ :

$$
\alpha=-\ln \frac{b_{a b s 1}}{b_{a b s 2}} / \ln \frac{\lambda_{1}}{\lambda_{2}}
$$

The Angstrom exponent has value about 1 for BC coming from FF and value about 2 for BC coming from BB [5]. This enables source apportionment of BC. For example, if the Angstrom exponent is measured to be 1.5, approximately $50 \%$ of BC comes from FF (primarily from diesel engines) and 50\% from BB (primarily from burning wood and coal). Main limitation of this approach is the fact that reference values of Angstrom exponent for FF and BB are not constant, and may vary from place to place and even for different season at the same place.

This technique is typically used at fixed research locations. Recently, pocket-sized aethalometers were developed, which opened new possibilities for mobile measurements (high spatial resolution measurements). This paper is one of the first experimental investigations using the advanced multi-wavelength aethalometer for mobile measurements of BC concentrations and Angstrom exponent based source apportionment studies. This technique has potential to discover sources of air pollution, which is very important step in solving the air pollution problem. Research question here is: can mobile aethalometer, such as MA200, distinguish between different sources of BC?

\section{Experimental setup}

Fig. 2 shows the experimental setup. Mobile aethalometer MA200 from AethLabs (San Francisco, USA) with an inhouse developed enclosure was used. This component was designed to complement existing systems for mobile measurements of particulate matter [6], [7], toxic gases [8], [9] and vertical measurements using unmanned aerial vehicles [10]. Basic specifications of MA200 are:

- 5 wavelengths: $880 \mathrm{~nm}$ (IR), $625 \mathrm{~nm}$ (Red), $528 \mathrm{~nm}$ (Green), $470 \mathrm{~nm}$ (Blue), $375 \mathrm{~nm}$ (UV)

- Dual-spot filter loading compensation

- $\quad$ Time base options: $1,5,10,30,60$, or 300 seconds

- Flow rate options: $50,75,100,125$, or $150 \mathrm{ml} / \mathrm{min}$

- $\quad$ Dimensions and mass: L $136.75 \mathrm{~mm}, \mathrm{~W} 85 \mathrm{~mm}, \mathrm{D} 35.75 \mathrm{~mm}$, mass $420 \mathrm{~g}$

- Additional sensors: pressure, temperature, acceleration, GNSS 
If the aethalometer uses single sampling spot at a time, some non-linear effects may appear as a consequence of filter loading effect. In most cases these effects are not too high, but they can be avoided using the so-called dual-spot mode, in which the device uses two spots with different loadings for each measurement.

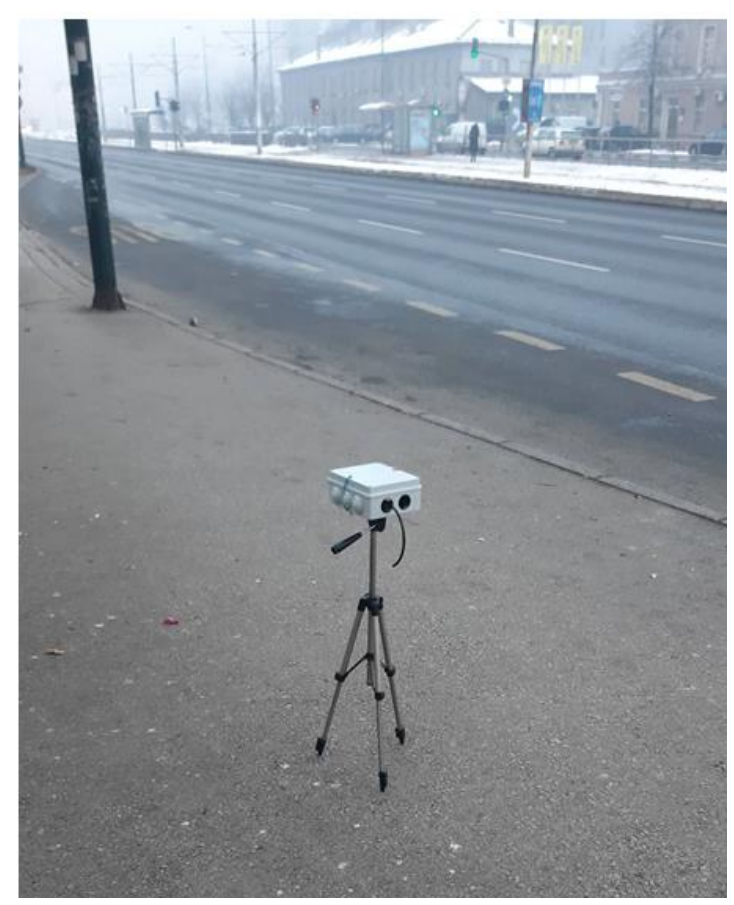

Fig. 2. Mobile aethalometer with enclosure

Table 1 shows locations of all measurements and ambient conditions. Location No.1 was near the main road, so we expect dominant contribution from vehicles here. Location No.3 is sub-urban area, for which we expect higher influence of BB sources. Other locations represent mix of FF and BB sources.

\begin{tabular}{|r|c|l|c|c|c|}
\hline No. & \multicolumn{1}{|c|}{ Date } & \multicolumn{1}{c|}{ Location } & Time & Air temperature & Mode \\
\hline 1 & $10 / \mathrm{JAN} / 2020$ & $\begin{array}{l}\text { Sarajevo }- \\
\text { University }\end{array}$ & $08: 04-08: 56$ & $-8{ }^{\circ} \mathrm{C}$ & Single-spot \\
\hline 2 & $11 / \mathrm{JAN} / 2020$ & Ilijaš & $11: 00-11: 40$ & $0{ }^{\circ} \mathrm{C}$ & Dual-spot \\
\hline 3 & $16 / \mathrm{JAN} / 2020$ & Hrasnica & $18: 41-19: 38$ & $-3{ }^{\circ} \mathrm{C}$ & Dual-spot \\
\hline 4 & $26 / \mathrm{JAN} / 2020$ & $\begin{array}{l}\text { Sarajevo - } \\
\text { Alipašino Polje }\end{array}$ & $08: 06-08: 57$ & $-1{ }^{\circ} \mathrm{C}$ & Dual-spot \\
\hline 5 & $31 / \mathrm{JAN} / 2020$ & $\begin{array}{l}\text { Sarajevo - } \\
\text { Alipašino Polje }\end{array}$ & $08: 03-08: 56$ & $-3{ }^{\circ} \mathrm{C}$ & Dual-spot \\
\hline 6 & $17 / \mathrm{FEB} / 2020$ & $\begin{array}{l}\text { Sarajevo - } \\
\text { Alipašino Polje }\end{array}$ & $15: 51-16: 44$ & $18^{\circ} \mathrm{C}$ & Dual-spot \\
\hline
\end{tabular}

Table 1. Locations of measurements and ambient conditions

\section{Results}

BC concentrations for measurement No.1 were extremely high: up to $50000 \mathrm{ng} / \mathrm{m}^{3}$ for IR channel (880 nm). Fig. 3 shows BC concentrations calculated for all wavelengths for measurement No.1. These results represent strong urban pollution. In order to analyze the source of this $\mathrm{BC}$, we need to calculate the Angstrom exponent. Fig. 4 shows the dependence of $\ln \left(b_{a b s}\right)$ on $\ln (\lambda)$. It follows from equation (5) that Angstrom exponent is actually the slope of this graph (without negative sign). From Fig. 4. we can see that correlation coefficient is very high, 0.9992 (dependence is almost perfectly linear), and the slope of the line of best fit is -1.078 .

Thus, the Angstrom exponent for this measurement is 1.078, which corresponds to dominant contribution of vehicles' emissions. If we assume that value 1.0 corresponds to FF and value 2.0 corresponds to $\mathrm{BB}$, we can estimate that $7.8 \%$ of $\mathrm{BC}$ comes from solid fuel and $92.2 \%$ of $\mathrm{BC}$ comes from liquid fuel (diesel) in this scenario. This is expected since the measurement No.1 was located near the main road. By repeating the same procedure, we can calculate Angstrom exponent for all measurements. Table 2 summarizes these results. As expected, location No.3 shows dominant contribution of BB, while other locations represent certain mix of FF and BB sources. 


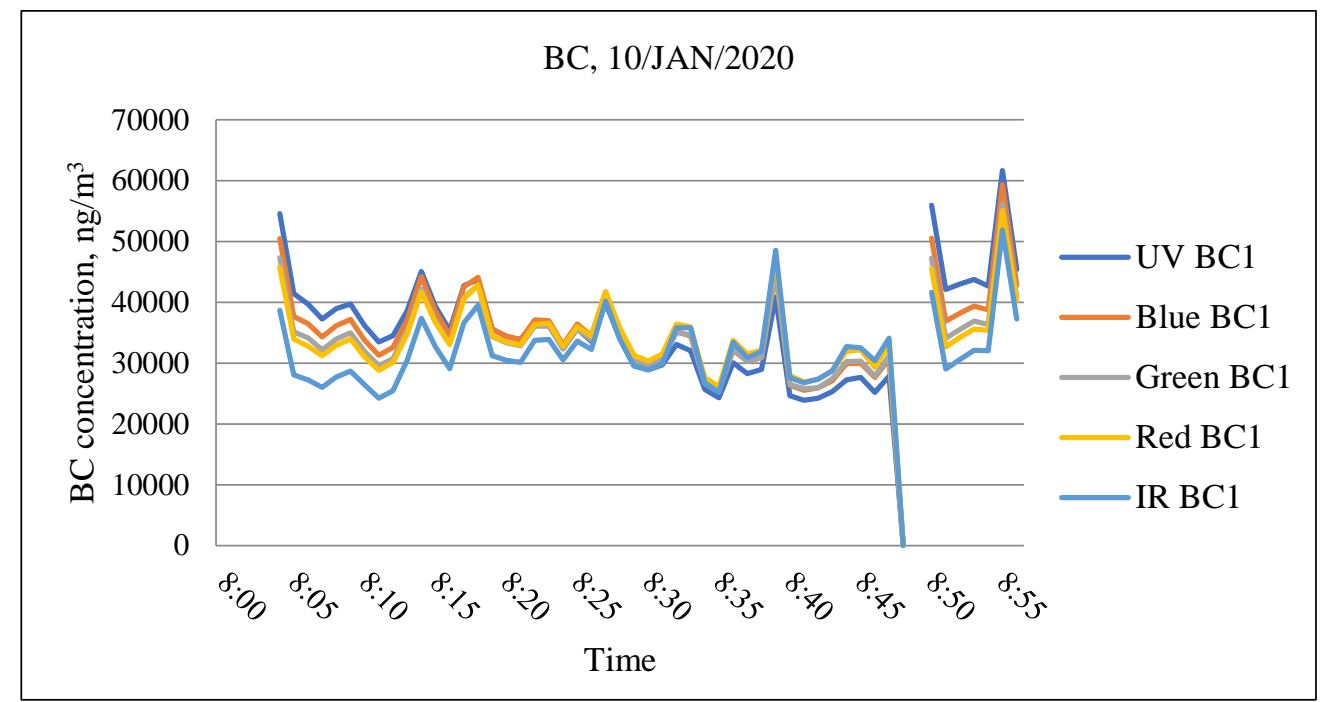

Fig. 3. BC concentration

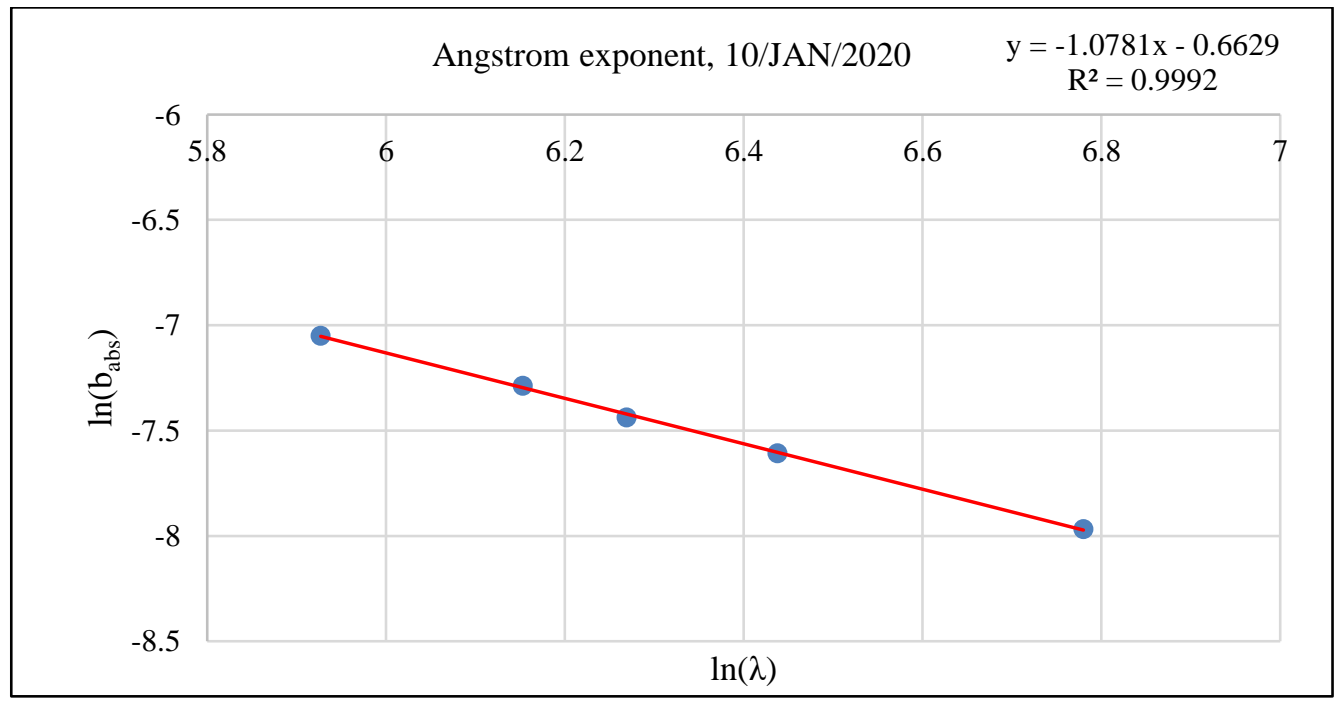

Fig. 4. Angstrom exponent

\begin{tabular}{|c|c|c|c|}
\hline Location & Angstrom exponent & Estimated BB contribution & Estimated FF contribution \\
\hline No.1 & 1.08 & $8 \%$ & $92 \%$ \\
\hline No. 2 & 1.52 & $52 \%$ & $48 \%$ \\
\hline No.3 & 1.75 & $75 \%$ & $25 \%$ \\
\hline No.4 & 1.43 & $43 \%$ & $57 \%$ \\
\hline No.5 & 1.31 & $31 \%$ & $69 \%$ \\
\hline No.6 & 1.22 & $22 \%$ & $78 \%$ \\
\hline
\end{tabular}

Table 2. Summary of all results

\section{Conclusion}

Novel method for mobile BC measurements and source apportionment studies based on Angstrom exponent is presented. The method was successfully tested in field campaign from 10/JAN/2020 to 17/FEB/2020, during the period of strong air pollution. MA200 aethalometer proved to be capable to measure high concentrations of BC and differentiate between FF an BB sources. Measurement near the main road showed dominant contribution of vehicles' emissions, while the measurement in the sub-urban area exposed dominant BB sources. But these values are approximate since we don't have the reference values of Angstrom exponent for local conditions.

In the future work new experiments should be carried out with the aim to isolate FF sources from BB sources and determine corresponding values of the Angstrom exponent. Vertical measurements across the inversion layer would be very useful too. 


\section{References}

[1] Zhang, H. \& Wang, Z. (2011). Advances in the study of black carbon effects on climate, Advances in Climate Change Research, Vol. 2, No. 1, pp. 23-30, DOI:10.3724/SP.J.1248.2011.00023

[2] World Health Organization (2012). Health effects of black carbon, Report, ISBN: 9789289002653

[3] Magee Scientific (2019). Aethalometer model AE33, User manual

[4] Kirchstetter, T. W. \& Novakov T. (2004). Evidence that the spectral dependence of light absorption by aerosols is affected by organic carbon. Journal of Geophysical Research, Vol. 109, DOI:10.1029/2004JD004999

[5] Sandradewi, J.; Prevot, A. S. H.; Weingartner, E.; Schmidhauser, R; Gysel, M. \& Baltensperger, U. (2008). A study of wood burning and traffic aerosols in an Alpine valley using a multi-wavelength Aethalometer. Atmospheric Environment, Vol. 42, No. 1, pp. 101-112, DOI: 10.1016/j.atmosenv.2007.09.034

[6] Masic, A.; Bibic, D. \& Pikula, B. (2019). On the applicability of low-cost sensors for measurements of aerosol concentrations, Proceedings of the 30th DAAAM International Symposium, pp.0452-0456, B. Katalinic (Ed.), Published by DAAAM International, ISBN 978-3-902734-22-8, ISSN 1726-9679, Vienna, Austria DOI: 10.2507/30th.daaam.proceedings.060

[7] Masic. A.; Bibic, D.; Pikula, B.; Blazevic, A.; Huremovic, J. \& Zero, S. (2020). Evaluation of optical particulate matter sensors under realistic conditions of strong and mild urban pollution. Atmospheric Measurement Techniques, Preprint, DOI: 10.5194/amt-2020-237

[8] Masic, A[dnan]; Bibic, D[zevad]; Pikula, B[oran] \& Razic, F[aruk] (2018). New approach of measuring toxic gases concentrations: principle of operation, Proceedings of the 29th DAAAM International Symposium, pp.0882-0887, B. Katalinic (Ed.), Published by DAAAM International, ISBN 978-3-902734-20-4, ISSN 1726-9679, Vienna, Austria, DOI: 10.2507/29th.daaam.proceedings.127

[9] Bibic, D[zevad]; Pikula, B[oran]; Masic, A[dnan] \& Razic, F[aruk] (2018). New approach of measuring toxic gases concentrations: application examples, Proceedings of the 29th DAAAM International Symposium, pp.0876-0881, B. Katalinic (Ed.), Published by DAAAM International, ISBN 978-3-902734-20-4, ISSN 1726-9679, Vienna, Austria, DOI: 10.2507/29th.daaam.proceedings.126

[10] Masic. A.; Bibic, D.; Pikula, B.; Dzaferovic-Masic, E. \& Musemic, R. (2019). Experimental study of temperature inversions above urban area using unmanned aerial vehicle. Thermal Science, Vol. 23, No. 6A, pp. 3327-3338, DOI: 10.2298/TSCI180227250M 